THE SIGNIFICANCE OF CONSTITUTIONAL VALUES

ISSN 1727-3781

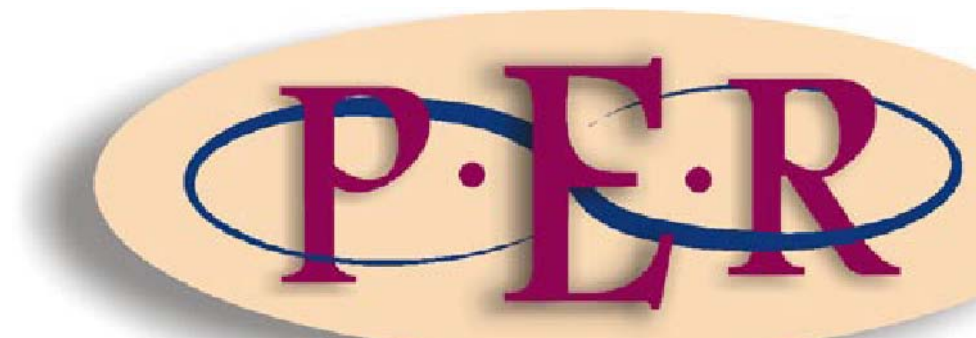

2001 VOLUME 4 No 1 


\title{
THE SIGNIFICANCE OF CONSTITUTIONAL \\ VALUES
}

\author{
Prof Hiroshi Nishihara LLD \\ Waseda University (Tokyo/JAPAN)
}

\section{Modern constitutionalism as an allegedly value-neutral system}

\subsection{Notion of "constitutional values"}

I would address the question about the significance of constitutional values. In order to fulfill this task, we have to begin with the question, "What on earth are constitutional values?" Is the adjective "constitutional" equivalent to the circumstance that the pouvoir constituant or the congress establishing the constitution happens to write those values into the text of the constitutional document? Such usage of the word "constitutional" presupposes the idea that a written constitution may raise any value to constitutional values, including, for example, a religious virtue in favour of some comprehensive confession. Or, are there any limitations to what we properly call constitutional values? For the latter, there follows the question about how and on what definition of the word "constitutional" we can limit the scope of constitutional values.

In the 21st century, the century of human rights as is anticipated by many, we cannot use the concept of constitutional values to signify arbitrary value judgment met by the drafter of constitutional documents. It is no longer allowed to legitimize the discriminatory and inhuman treatment of people in the name of constitutional values. There exists also a consensus all across the globe about the fairness of democratic process and unfairness of the deprivation of political rights. Therefore, if we speak of constitutional values, we take for granted a certain frame of reference as to what belongs to these values. This is the very fact resulting from the effort of a lot of nations, during and after the Cold War, to establish a free and democratic government, including the effort of the Republic of South Africa to "heal the divisions of the past", as it reads in the preamble of its final Constitution.

However, problems relating to constitutional values and their legal significance are by no means already solved by the existence of this overwhelming consensus. In reality, the 
case is quite the contrary. There is namely only a vague framework of what can be legitimately called "constitutional". Every constituent convention may stress these or those aspects among existing values that can be recognized as "constitutional". Consequently, the design of a political entity as a result of constitutional choice differs a great deal from nation to nation. Nor is it only a matter of making a new constitution. Constitutional provisions are always interpreted according to the Zeitgeist, the dominant idea of a time, so that the fundamental rights and requirements of the democratic process mean, even within a single constitution, something different from time to time. We need, therefore, some frame of reference in order to confine ourselves within the proper interpretation of constitutional rights and principles.

Without a system of constitutional values, the constitutional praxis would run the risk of favouring one particular value and right in a biased manner and pervert them to something totally opposite, into legitimation of injustice in the name of constitutional law. Such would be the case if the value of democracy justifies a dictatorship grounded on one-way popular election (as Hitler's regime was defended to be democratic), or if the values of equality are realized by state planning which guarantees perfect equality of result, rejecting human freedom.

Professor Venter's well-known effort ${ }^{1}$ should be understood in this context. In his thesis presented in this symposium three years ago, he developed a hierarchical system of values, which were enumerated in section 1 of the South African Constitution. This provision demands the Republic of South Africa to be founded on these values. In his hierarchy, professor Venter assigned the value of human dignity to the very core and understood equality and freedom as the supporting values, while democracy and rule of law are the structural values. This effort builds up a system of constitutional values. As we can see from this effort, values appropriately identified as "constitutional" construct a certain framework of a legitimate form of government, but we should always be careful not to deviate from the system of fundamental constitutional values. Setting up Auslegungsmaxime, general rules of interpretation, constitutional values contribute to proper understanding of constitutional provisions. 


\subsection{Freedom, equality and democracy as value-neutral criteria of fairness}

The framework of constitutional values has been, somewhat vaguely, established in the consensus of most nations. In any case, the system of constitutional values builds an oval with two central points: the substantive value of human rights and the procedural value of democracy. Section 1 of the South African Constitution is also devoted to the fulfillment of this value system.

But, here we are faced with a question. Why do the values of human dignity, freedom and equality deserve more respect than other values? Are they, in their nature, superior to other religious, ethical and cultural values? If so, to what extent? The history of constitutional values in the 20th century has actually been a history of challenges against them. Challenges from a totalitarian point of view and those based on religious motivations have characterized the debates on fundamental rights.

To answer these questions, it is not enough to affirm the notion of human dignity, however important it may be. Every religious doctrine has its own idea about human nature that can come into conflict with the constitutional understanding of human dignity. Similarly, there are values that are allegedly rooted in the culture of each country. If the anthropological background of cultural values were considered to be relevant in forming legal order, it would be hard to establish the supremacy of constitutional values based only on the notion of human dignity. Equality, freedom and democracy are values also characterized by their origin in the culture of European Christianity. Why should the Christian cultural values prevail over other culturally founded values?

One of the most convincing answers to this question emphasizes the value-neutral character of freedom, equality and democracy. These values designate only some rules in reconciling value conflicts among the people instead of establishing a certain comprehensive doctrine as an officially recognized belief. They leave enough room for every individual to design his/her own life according to his/her belief and bind only communication in the public sphere to some formal rules.

Of course, constitutional values are not fully procedural, as John Hart Ely asserted in relation to the heightened judicial review grounded on some fundamental rights. He 
understood the strict scrutiny applied by the US Supreme Court to be a reinforcement of the democratic process. Legislation curtailing, for example, the freedom of expression or the equality rights of separate minority groups damages the process of democratic decisionmaking itself and therefore deserves especially careful control by the courts. Although this opinion can justify the scrutiny based on fundamental rights without favouring certain values, it cannot be applied to answering the question as to why constitutional values require more attention than other cultural, moral and metaphysical values, for Ely's thesis takes for granted the validity and legitimacy of democratic process and does not analyze the structural preconditions of democratic governance.

Rather, constitutional values are substantive in their nature. It does not mean that such values always construct a system that embrace the entire scope of human life. For example, freedom as a constitutional value does not necessarily demand a lifestyle of autonomy and independence. It also acknowledges a devotion to religious or cultural values and permits people's obedience to some absolute authority. What the constitutional notion of freedom does not allow, is the state's coercing people into such independent forms of life.

Ronald Dworkin ${ }^{2}$ expressed such a limitation of state activity as neutrality on the question of good life. According to his opinion, government treating its citizens as equals must be as independent as possible of any particular conception of good life. Since every citizen of a society differs in his/her conception, the government does not treat its citizens as equals if it prefers one such conception to another. John Rawls developed this idea and introduced a formula of the "neutrality of aim". The government cannot be neutral in the effect of its activity, but, in his view, justice as fairness hopes to satisfy the neutrality of aim in the sense that basic institutions and public policies are not to be designed to favour any particular comprehensive doctrine.

In the contemporary world, the factual plurality of moral and ideological conceptions 
among people must take precedence to legal order. In terms of this plurality, a government has only two choices: either it fully relies on a certain comprehensive doctrine and tries to maintain ideological unity among its subjects, or it bets on the potential ability of the people to live autonomously and guarantees freedom and equality. Attachment to constitutional values leads to abandoning the first alternative, which may result in some collectivistic regime.

If a constitutional state seeks to secure the good order by guaranteeing the freedom of conscience, it would be disruptive to have its own moral position underlying its activities. In order to keep sound social order, it is in the interest of the state to seriously consider the condition on which its citizens may exercise the freedom of conscience. Similarly, it would be impossible to treat people from different cultural backgrounds equally if the state presents itself as an institution of one particular culture.

\subsection{Individualistic view of constitutional values}

The notion of human dignity upholds, as we have seen, the primary value of the constitutional system. In contemporary society, this notion may not be understood in relation to a particular comprehensive doctrine. Instead of relying on such a perfectionistic argument, constitutional values should defend themselves as founding a value-neutral framework for reconciling social antagonism. The central idea of human dignity should then be sought in the equal quality of every individual against autonomous judgment. This assessment leads to some theoretical conclusions. Interpreting constitutional values from this fundamental viewpoint amounts to an individualistic understanding of freedom and equality.

The concept of freedom can cover a wide range of human desire. However, not all of them could be legitimately considered as constitutional values. Particularly, the question of whether and to what extent fundamental rights include the so-called positive freedom must be addressed for every constitutional system. To illustrate this problem, let us consider a German case of the crucifix in the classroom. In the German theory, religious freedom also includes positive freedom, the freedom of the Christian majority to have their religion officially supported within the institution of public schools. Of course, such governmental support of one particular confession amounts to a clash with the negative freedom of non- 
Christian minorities. The German Federal Constitutional Court ${ }^{4}$ gave priority to this negative freedom. It condemned a statutory provision requiring schools to hang a crucifix in their classrooms, on the premises that such practice violates the right of young citizens to develop their confession without intentional influence by the government. This decision met a passionate criticism resting on the notion of positive freedom, but the court was unable to give priority to the will of the majority.

In countries where church and state are constitutionally separated, such as the United States, France and Japan, it would be impossible for positive freedom of the majority to wear the mask of constitutional rights. The principle of this separation establishes, in the limited sphere of religion, the neutrality of the state. A state that wishes to guarantee maximal religious freedom should abandon its own confession and treat each religion equally. Otherwise, governmental actions based on an official religion could not avoid exercising negative influences on the religious growth of its citizens.

Needless to say, governmental neutrality cannot be understood to include neutrality in effect. The separation of church and state, even if it is adopted in the constitution, applies only in relation to institutionalized religions such as the Christian church or Muslim organizations. Outside this realm, neutrality disqualifies only intentional identification with certain religious, moral or ideological doctrines. To punish a murder means, of course, to adopt a moral view that murder constitutes an evil. This is only justified if the government is interested in preventing an actual harm to the life of its citizens. It would be difficult to support such governmental actions seeking to maintain moral beliefs among the people.

In the face of this fundamental neutrality, the notion of constitutional freedom does not include the positive will of the majority to reflect their own confessions in the state institutions. Such a desire demands something impossible to the state, because it may not identify itself with one particular confession even though the confession is shared by a majority of its members. The state can and does realize the majority's

5 Cf Nishihara 2000 Der Staat 39, 86. 
interests expressed through the process of democracy, but only to the extent that such interests can be put into rational terminology. When the majority pursues goals only explainable on the basis of a certain system of ideological thought, they are beyond the reach of the secular state. 1

Similarly, the notion of equality should be defined as an individual right if the core idea of human dignity could be sought in the equal quality of every individual. To what kind of group an individual happens to belong is a fully irrelevant issue in law. The constitutional guarantee of equality requires every individual to have an equal chance in selfdetermination. This also ties in with the fundamental neutrality of the state. The state should always try to be color-blind and sex-blind in allocating benefit and burden among its citizens.

In the South African context, this thesis would support - in spite of professor Fagan's 6 criticism - the dignity-analysis of "unfair discrimination" in the sense of the Prinsloo 7

judgment. Here, Ackermann, O'Regan and Sachs interpret the "unfair discrimination" prohibited in section 8 (2) of the interim Constitution (or section 9 (3) of the final Constitution), in reliance on Goldstone J's theory in the Hugo judgment ${ }^{8}$ and also in reliance on Dworkin's definition of dignity, ${ }^{9}$ as prohibiting a differentiating treatment of people which impairs their fundamental dignity as human being. ${ }^{10}$ In rejecting this position, professor Fagan maintains that this dignity-analysis would amount to be too strict, so strict that this provision would be unable to play the expected central role in South Africa. The Interpretation of the "unfair discrimination", however, cannot lose connection to the system of fundamental constitutional values with human dignity at

6 Fagan 1996 SAJHR 220. His opinion is influenced by Westen's theory. Cf Westen 1982 HarvLR 95, 537. Professor Fagan demands, on this theoretical Background, "unfair" discrimination to be one that infringes either an independent constitutional right or a constitutionally grounded egalitarian principle. The first requirement - even sometimes observed, for example in a 14 of the European Convention of Human Rights - leads to limit the application of the equality clause to cases in which some independent constitutional rights are violated and to make the equality clause superfluous. Because he demands the second requirement, his criticism of the dignity analysis amounts only to be postponed. Furthermore, the justice-oriented understanding of equality as professor Fagan puts forward is now criticized by the right-oriented understanding of equality, which tries to establish a proportionality test within some limited area such as gender and racial discrimination. Such effort can at best observed in the judgements of the Court of European Communities. Cf Nishihara "Two Models of Equality".

$7 \quad$ Prinsloo $v$ Van der Linde 1997 (3) SA 1012 (CC) par 31-32.

8 President of RSA $v$ Hugo 1997 (4) SA 1 (CC) par 41.

9 Dworkin op cit (n 2) 191.

10 Cf Grupp Südafrikas neue Verfassung 47-49. 
the center of the system. This is also shown in the fact that professor Fagan himself introduces the reference to Dworkin's definition of dignity in interpreting the dignity clause in section 10 of both interim and final Constitutions and thus incorporates this understanding of dignity in construing section 8 (2).

Furthermore, it makes no sense in the legal order to speak of the parity of different racial, ethnic or cultural groups. As a neutral state treats each individual as an equal member of its society, it cannot recognize groups as such. The only exception to this principle would be the statutes providing for the possibility of affirmative action. But in this field as well, a group-oriented approach is not appropriate.

Although we know that the problem of discrimination applies only to certain groups, discriminatory praxes are not unfair because they treat each group differently. Actually, they violate the fundamental right to equal respect, because they disregard each individual's worth according to his/her ability and achievement and evaluate a person superficially based on his/her group membership, which has nothing to do with individual performance. Remedial measures should, therefore, counterbalance any stereotyped judgment.

The prevailing view on affirmative action plans interprets them as measures to compensate historical evil done to the discriminated group. Reverse discrimination resulting from such plans is, according to this view, tolerable insofar as it curtails the ruling group's benefit that would not have been due to them but for the discrimination in the past. This view only tries to compensate past evil through creating new evil. It cannot justify the special burden on a particular individual who does not have personal responsibility for the past discrimination and who usually comes from a discriminated segment of the privileged group. The goal that an affirmative action plan may properly pursue in the framework of constitutional values is to counterbalance the contemporary influences of discrimination toward a person from a traditionally discriminated group.

In such a way, the concepts of freedom and equality understood individualistically serves as elements of the value-neutral system for reconciling racial, cultural or moral conflicts. In the modern world, citizens develop their personal identity on the basis of their different, or even conflicting beliefs and cultural background. We need a legal system that can make possible the coexistence of individuals within this plurality of opinion. Constitutional values deserve 
to be called "constitutional" if and because they are indispensable to the system guaranteeing peaceful coexistence.

\section{Value-neutrality as a culturally conditioned value?}

\subsection{Challenges from collectivistic notions}

In establishing the theory about the neutrality of aim in his book on "political liberalism", Rawls presupposes existence of overlapping consensus among citizens and reasonable doctrines in a well-ordered society. We are, however, not always dealing with well-ordered societies. In the contemporary world, most countries represent only a weak consensus in favor of constitutional values. They are always challenged by many kinds of ideas.

The most direct challenge comes from different forms of collectivism. Totalitarian regimes in the past, such as Fascism in Europe in the 1930s, are the best examples. A totalitarian dictatorship is not a historical fact. There are also many countries today under military dictatorship, where the citizens are often excluded from political decision under a one-party system.

However, there are countries that are, at first glance, democratic in its political structure but are still under the influence of collectivism. In such cases, totalitarian regimes are in some sense democratic. Where the majority feels free to exercise power on the minority without being limited by legal order and without worrying about the accountability, their attitude toward the minority tends to lose control. In several countries, the moment of violence expresses itself less directly but more indirectly through the social mechanism.

One example of this social mechanism is a particular idea of equality. There are societies where individual freedom is misunderstood as an arbitrary request of self-willed individuals out of egoism. If the ruling group is convinced by such a view, the notions of rule of law and equality are sometimes drawn into perversion. Originally, the principle of rule of law intends to subject governmental power to law to prevent the arbitrary use of such power and thus to protect the fundamental rights and interests of citizens. In some Asian countries, such as Japan, the concept of rule of law is sometimes misconstrued. Where this principle is traditionally misused in order to legitimize the ruling by law, individual freedom has no place in the system. Equality means, then, equality in obligation. Based on this understanding, the government is prevented from allowing exceptions for individuals who assert their rights of 
freedom, even in order to guarantee equality. One typical example of such a sophisticated form of totalitarian regime can be observed in Japan. In the early years of its democracy after World War II, it failed to divide the continuity of social structures. People were still dependent on the moral and economic instruction of the imperial government. The dependence was founded first in the era of this country's modernization in the late 19th century and strengthened before and during the war. Also under the new democratic constitution of 1946, Japan failed to establish a proper concept of freedom, mainly because those constitutional theories put too much emphasis on the realization of social rights and acknowledged a national unity of interests that should be fostered by government control.

In such a sophisticated collectivism, people who express their awareness in the irrationality of the dutiful structure, run the risk to be excluded from social life. It is, certainly, much better than the direct application of violence by the state. In Japan in the 1930s and 1940s, social criticism often led to death following horrible torture. In comparison, contemporary Japanese do not have to worry about their life when, for example, they express dissatisfaction toward the governmental praxis by rejecting to sing the national anthem. What they have to worry about is, maybe, their career in their company, or their school records. The slightness of punishment makes the unfair praxis less notable, but this still does not make it fair.

Such praxis is based on the notion that people do not always deserve equal respect. There is conduct that is wrong, leaving no space for excuses; people who engage in such conduct deserve no respect, because they are unable to respect common sense. The distinction between right and wrong, then, depends on the judgment of authority, which normally consists of persons in leading positions that have authority over subordinates. In the framework of such authoritarian thought, the weaker the position of an individual, the stronger the power applied. Notwithstanding the Japanese notion of equality in obligation, an authoritarian society is by no means a fair society. 
In Japan, this authoritarian structure comes from the continuity of power exercised by the elite since the era of Fascism before World War II. Some say that the existence of an imperial system lies behind such authoritarian thought and that the Japanese people cannot free themselves from it without abolishing this typical example of feudalism. It may or may not be true; the collectivism in Japan is clearly the remains of an outdated model. This does not mean that it is easy to overcome collectivism, partly because it represents a convenient system for the majority of the society. Today, more than ever, the Japanese government can however no longer avoid respecting personal freedom. It cannot be held responsible for the economic prosperity of every citizen any more, because the process of globalization affects Japan much more than Japanese bureaucracy can somehow control. At this stage, the Japanese government cannot but respect the free choice of every individual.

Such a development is probably not limited to Japan. The background of the Japanese system was cultural influences of Confucianistic ethics and Buddhistic religion, which supported the moral duty to obey one's superior. Some Asian nations have, at least partly, the same cultural background. Now we can see in several Asian countries concentration of power for the sake of economic development, which is the result of their cultural background, if applied to their economic conditions. But this common form of Asian dictatorship shares the fate with its model of Japanese bureaucracy, as is already shown most typically in the development in Indonesia.

\subsection{Communitarian view of individual freedom}

The antagonism between individualism and collectivism is rooted in a metaphysical conflict: is a human being properly understood to be the master or only a dependent member of a social group? Individualism tends to adopt the first view, demanding rationality to be the inherent ability of every individual. This view is criticized by many forms of communitarian thought. The latter maintains that personality does not precede membership in a society, but is only an outcome of the person's development in his/her society. Such a theory acknowledges no culturally neutral values. 
This fundamental idea first leads to a republican understanding of personal freedom. Republicanism tends to define persons to be members of a nation; their personalities are determined by the national culture, expressed most clearly in its language; the nation-state is a process of integrating such cultural unity. ${ }^{12}$ From these fundamental ideas, republicanism explains why a nation-state guarantees the freedom of every individual. Freedom does not intend to enlarge individual arbitrariness; rather, its aim lies in the intention to let every member of the nation contribute in his/her way to the nation. Since individual members have different abilities, it is efficient for the national body to leave many ways open to contribute to the national society. However, a limitation of freedom is inherent to this interpretation. Since it looks like nonsense to make personal arbitrariness possible, freedom may only be guaranteed in relation to conduct that benefit the nation, evaluated according to the cultural measure of respecting society.

If there were a nation-state in the right sense of the term, that is a closed society of people sharing a fundamental belief and rule, it might be possible to understand personal freedom in favor of this republican view. Nevertheless, there is no such closed society in the world today. Every country has a population from multicultural backgrounds. There are always people with different beliefs and ideologies. Within such a plurality, the significance of constitutional values lies not in maximizing the contribution to national culture at the expense of the rights and interests of minorities, but in making peaceful coexistence possible.

The republican view takes national unity as granted. Such theoretical prerequisite is at best criticized by multiculturalism and feminism. It is interesting, however, to note that these beliefs share the same metaphysical understanding of human nature with republicanism. Feminism asserts the cultural difference between men and women and criticizes the traditional social order as that of masculine culture. Similarly,

11 Nishihara and Kim Vom paternalistischen zum partnerschaftlichen Rechtsstaat 25-36.

12 Smend Staatsrechtliche Abhandlungen. 
multiculturalism seeks to overcome the dominance of one particular - Western -culture over others. In doing so, they explain the personality of human beings as an outcome of cultural identity. The difference between multiculturalism and feminism on the one hand and republicanism on the other lies only in the answer to the question what kind of group serves as a frame of reference in finding the determining factor for personal identity.

For that reason, the same question applies also to multiculturalism and feminism. Is there any closed group of one particular culture? Not all women share a single culture; every woman is determined under the influence of various cultural elements, such as her nation, her gender, her sex, her local community, her school, her classmates, her standing, her family, and what she finds personally suitable for herself. Similarly, there is no closed culture of one racial or ethnic group. It is an established fact that the range of personal differences is much larger than that of cultural difference.

Given this fact, it is not appropriate to accept these communitarian views of human nature in establishing a fair order for a political society. If an individual is considered to be a member of a certain cultural group, he/she is compelled to be a fighting member of his/her group. But, in reality, he/she is always a member of several groups at the same time. It seems fatally impossible for a pluralistic view of political fairness, which looks for good order to a well-balanced allocation of power among relevant groups, to take all forms of culture into consideration. Cultural balance is something that cannot be realized, and it would be nonsense to pursue such a balance. As we have seen in relation to the grouporiented understanding of equality rights, only every individual counts.

\section{A cosmopolitan view of freedom and the right to peace}

The metaphysical question about the correct way to understand human nature cannot be answered here. Certainly, the individualistic concept of freedom and equality prefers to some extent an individualistic position in the metaphysical discussion. But this combination is not necessary. 
In seeking a fair constitutional order, we have to consider why on earth we need something like constitutional values. As I have already repeated several times, it is because we have to find a way for a peaceful coexistence of conflicting, even antagonistic comprehensive doctrines and cultures. There is, therefore, no point in rejecting the fact of confessional plurality and trying to go back to the world of cultural unity. Instead, we must be aware of the fact that every individual forms his/her identity under the influence of cultural, religious and moral plurality.

This does not deny the worth of evaluating human conduct according to its contribution to a greater entity. Now that we have rejected the closed society of a single culture as a reference for this measurement, we can only look at the global community of human beings as a proper source of all values. ${ }^{13}$ It is the only way to avoid antagonism among the cultures and establish peaceful coexistence, without always regarding individuals as soldiers of cultural groups struggling for dominance.

When the Japanese Constitution established in 1946 declared the right of the people to live peacefully and put it in a concrete form of constitutional disarmament, it had the cosmopolitan concept of fundamental rights in mind. War is the most severe violation of human rights, demanding the sacrifice of the citizen's life for the sake of some allegedly overriding national interest. From the victim's point of view, it makes no sense to justify war in the name of overriding benefits. It was at least necessary, then, in the national interest to reject status as the last and highest source of values. The pacifist clause in article 9 of the Japanese Constitution has not been realized yet in the alliance between Japan and the United States, and it is now challenged by the movement of constitutional revision. Revisionists argue that Japan need to be armed with highly-developed weapons in order to contribute to the maintenance of world peace. Even in pursuing this goal I think we also have to be aware of the significance of the constitutional prohibition for the state to be armed.

Certainly, only physical power makes the maintenance of good order possible. Also, it goes without saying that every state should protect the safety of the social life of its citizens. It is, however, highly questionable whether modern states can properly solve the problems alone. We need, rather, a global organization independent of national interest, an organization in which not every state, but every individual all across the globe is represented. 
At the end of the 20th century, we have reached a stage where we have to establish constitutional values at a global level. Those values with the same components should now be respected nationally and supra-nationally. Individual rights such as freedom and equality as well as the procedural principle of democracy should always be central to political judgments. This is because we can only guarantee peaceful coexistence on the basis of those constitutional values.

We have had to observe that those constitutional values are not respected as they ought to be all over the world. Though there are still a log of difficulties, partly difficulties of totally different kind, I hope we can continue to collaborate in further establishing constitutional values in our states and also at the supra-national level. 


\section{$4 \quad$ Bibliography}

Dworkin A Matter of Principle

Dworkin R A Matter of Principle (Harvard University Press Cambridge 1985)

Fagan 1996 SAJHR

Fagan A "Dignity and Unfair Discrimination: A Value Misplaced and a Right Misunderstood" 1996 SAJHR 220

Grupp Südafrikas neue Verfassung

Grupp T Südafrikas neue Verfassung (Nomos Baden-Baden 1999)

Nishihara 2000 Der Staat 86

Nishihara H "Die Trennung von Staat und Religion in der japanischen Verfassung" 2000 Der Staat 39, 86

Nishihara Two Models of Equality

Nishihara $\mathrm{H}$ "Two Models of Equality" in Waseda Bulletin of Constitutional Law

13 Nussbaum Preface 1. 2000 Papers presented at the $5^{\text {th }}$ World Congress of the IACL in Rotterdam 1999

Nishihara and Kim Vom paternalistischen zum partnerschaftlichen Rechtsstaat Nishihara $\mathrm{H}$ and Kim SS Vom paternalistischen zum partnerschaftlichen Rechtsstaat (Nomos Baden-Baden 2000)

Nussbaum Preface

Nussbaum M "Preface" in For Love of Country: Debating the Limits of Patriotism (Beacon Press Boston 1996)

Rawls Political Liberalism

Rawls J Political Liberalism (Columbia UP New York 1993)

Smend Staatsrechtliche Abhandlungen Smend R Staatsrechtliche Abhandlungen 
(Duncker und Humblot Berlin 1968)

Venter Hierarchy of Constitutional Values

Venter F "A Hierarchy of Constitutional Values" in Konrad Adenauer Stiftung

Constitution and Law: Seminar Report III (Johannesburg 1997)

Westen 1982 HarvLR Westen P "The Empty Idea of Equality" 1982 HarvLR 95, 537

Register of acts

Constitution of Japan 1946

Constitution of the Republic of South Africa 1996

\section{Register of cases}

BVerfGE 93, 1 (1995)

President of RSA v Hugo 1997 (4) SA 1 (CC) 41

Prinsloo v Van der Linde 1997 (3) SA 1012 (CC) 31-32 